\title{
What are the factors associated with sarcopenia-related variables in adult women with severe obesity?
}

Erika Aparecida Silveira ${ }^{1 *} \mathbb{D}$, Jacqueline Danesio de Souza ${ }^{2,3} \mathbb{B}$, Annelisa Silva e Alves de Carvalho Santos ${ }^{1}$ (D), Andrea Batista de Souza Canheta ${ }^{1}$ (D), Valéria Pagotto ${ }^{1}$ (D) and Matias Noll ${ }^{1,4}$ (D)

\begin{abstract}
Background: Understanding the association between sarcopenia-related variables and several risk factors may help to implement interventions aimed at preventing its occurrence by reducing or controlling the identified risk factors. Although changes in body composition occur in both sexes, in women, muscle loss is accentuated due to decreased estrogen levels following menopause. This study aims to determine the factors associated with sarcopenia-related parameters in middle-aged women identified with class II/III obesity (body mass index [BMI] $\geq 35 \mathrm{~kg} / \mathrm{m}^{2}$ ).

Methods: The study included 104 women with severe obesity ( $40.23 \pm 8.49$ years) with an average body fat percentage of $52.45 \pm 4.14 \%$. Sarcopenia was assessed using total appendicular skeletal muscle mass (ASMM), appendicular skeletal muscle mass index (ASMMI), and appendicular skeletal muscle mass adjusted by BMI (ASMM/BMI) as evaluated using dual energy X-ray absorptiometry (DXA). Hand grip strength (HGS) and HGS adjusted by BMl (HGS/BMI) were evaluated using dynamometry. Functional performance was assessed using the walking speed test (WS). The explanatory variables were age, lifestyle, comorbidities, food consumption, and metabolic parameters. A multivariate linear regression was performed.

Results: Factors associated with sarcopenia-related variables in 104 severely obese women with a mean BMl of $43.85 \mathrm{~kg} /$ $\mathrm{m}^{2}$ were as follows: ASMMI negatively correlated with serum levels of tetraiodothyronine (T4) and tobacco use; ASMM/ BMI negatively correlated with age, serum T4 levels, and diabetes; ASMM negatively correlated with T4 serum levels and diabetes; HGS negatively correlated with age and hypercholesterolemia, and positively correlated with low-density lipoprotein cholesterol (LDL-C); HGS/BMI negatively correlated with age and hypercholesterolemia and positively correlated with LDL-C; and WS negatively correlated with hypothyroidism and diabetes.

Conclusion: In severely obese women, muscle mass and function were inversely associated with age, smoking status, endocrine parameters, hypercholesterolemia, and comorbidities such as diabetes. Thus, the results of this investigation are relevant in supporting the development of clinical interventions to aid in the prevention of sarcopenia in adult women with severe obesity.
\end{abstract}

Keywords: Sarcopenic obesity, muscle mass, Muscle strength, Walking speed, metabolic diseases

\footnotetext{
* Correspondence: erikasil@terra.com.br

${ }^{1}$ Health Science Post-Graduation Program, Faculty of Medicine, Universidade

Federal de Goiás, 1a. s/n - Setor Leste Universitário, Goiânia, Goiás CEP

74605-020, Brazil

Full list of author information is available at the end of the article
}

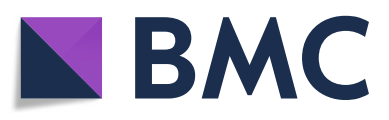

(c) The Author(s). 2020 Open Access This article is licensed under a Creative Commons Attribution 4.0 International License, which permits use, sharing, adaptation, distribution and reproduction in any medium or format, as long as you give appropriate credit to the original author(s) and the source, provide a link to the Creative Commons licence, and indicate if changes were made. The images or other third party material in this article are included in the article's Creative Commons licence, unless indicated otherwise in a credit line to the material. If material is not included in the article's Creative Commons licence and your intended use is not permitted by statutory regulation or exceeds the permitted use, you will need to obtain permission directly from the copyright holder. To view a copy of this licence, visit http://creativecommons.org/licenses/by/4.0/ The Creative Commons Public Domain Dedication waiver (http://creativecommons.org/publicdomain/zero/1.0/) applies to the data made available in this article, unless otherwise stated in a credit line to the data. 


\section{Background}

The concept of sarcopenia initially focused only on physiological aging and the decline of skeletal muscle mass [1]. The current evidence suggests that sarcopenia affects both older and younger adults [2]. Mass, strength, and muscular function are considered the main components to consider when making a diagnosis of sarcopenia [3-5]. Present efforts seek to understand the different mechanisms associated with muscle mass reduction and the progressive loss of muscle strength and function [6]. In this context, the presence of obesity, marked by excess adipose tissue, is related to muscle mass loss and contributes to the development of functional and physiological impairments [7-9]. However, there are a variety of propositions and discussions regarding assessment, diagnosis, and cutoff points to define sarcopenia, which hinders accurate comparisons, adequate understanding of the associated factors, and deepening understanding of their relationships with obesity $[10,11]$.

Obesity is increasing worldwide, and the prevalence of obesity class II (Body Mass Index $[\mathrm{BMI}]=35-39.9 \mathrm{~kg} /$ $\mathrm{m}^{2}$ ) and III (BMI $\geq 40 \mathrm{~kg} / \mathrm{m}^{2}$ ) has been rising alarmingly faster than that of class I [12]. The highest obesity class is a major public health problem associated with increased health problems and early deaths. Sarcopenic obesity, characterized by simultaneous muscle mass loss and increased body fat, has been recognized as a condition that requires greater clinical attention due to the unfavorable outcomes that can lead to disability, difficulty in carrying out daily activities, and increased mortality [13-15]. Despite the clinical importance of the two simultaneous conditions, obesity and sarcopenia-related parameters, few studies have analyzed this conditions in middle-aged adults $[16,17]$ and mainly in severely obese individuals $[14,18]$. Previous research suggests that poor nutrition is an underlying cause of sarcopenia and that dietary interventions may prevent or treat the loss of muscle mass and strength $[6,19]$. However, the clinical, metabolic, and lifestyle factors associated with these parameters have not been fully elucidated [20]. Another point that is important to investigate is the intake of some food sources of antioxidant vitamins, such as vitamins $\mathrm{C}, \mathrm{D}$ and $\mathrm{E}$, can be associated with muscle mass, functionality, and strength [21, 22].

Understanding the association between sarcopeniarelated parameters with several risk factors may help implement interventions aimed at preventing its occurrence by reducing or controlling the identified risk factors [23, 24]. Although changes in body composition occur in both sexes, in women, muscle loss is accentuated due to decreased estrogen levels following menopause $[25,26]$. Considering that the adult and elderly population is increasing rapidly worldwide and that women have a higher life expectancy than men, a higher prevalence of obesity and sarcopenia may be observed among women in the future. Therefore, recognizing the factors that contribute to sarcopenia in severely obese young adult women is relevant to directing protective measures to this population group [27]. The results of this study can help clinical obesity treatment settings to prevent sarcopenia and poor health outcomes, such as increasing early mortality Thus, the purpose of this study is to investigate factors associated with the sarcopeniarelated parameters in adult women with severe obesity (class II/III).

\section{Methods}

\section{Study design}

This study analyzes baseline data from the clinical trial "Effect of nutritional intervention and olive oil in severe obesity (DieTBra Trial)" [28] (project registered at ClinicalTrials.gov [NCT02463435]). Other results from this multidisciplinary clinical trial have already been published [29-34].

Inclusion criteria were female sex, BMI $\geq 35 \mathrm{~kg} / \mathrm{m}^{2}$, age between 18 and 65 years, and residence in the metropolitan area of Goiania, Brazil. Individuals were referred to the Nutrition in Severe Obesity Outpatient Clinic, and the study took place at the Clinical Research Unit of the Clinical Hospital at the Federal University of Goiás. Exclusion criteria were individuals that have had bariatric surgery, pregnant and/or lactating women, physical disability, weight loss $\geq 8 \%$ in the past 3 months, under nutritional/medical follow-up for weight loss for the past 2 years, and current use of anti-obesity drugs. Those who did not meet the specifications for performing body composition tests on the equipment dual energy X-ray absorptiometry (DXA), e.g., those with a pacemaker and/or metal rods and/or screws in the body, were also excluded.

\section{Sarcopenia-related variables: muscle mass, muscle strength and walking speed test}

Muscle mass was evaluated using DXA (GE Healthcare, Lunar DPX $\mathrm{NT}^{\oplus}$, Madison, USA). The half-scanner protocol (hemiscan) was used in patients who were larger than the bed edge limits of the DXA device $(>1.03$ $\mathrm{m})$. This protocol includes automatic duplication of the right side to obtain the total body composition. The device was calibrated daily. For the DXA scans, participants were advised to fast for $12 \mathrm{~h}$ before the exam; not to perform any physical activity; not to consume energy drinks, coffee, tea, or soda one day before the exam; not to drink alcoholic beverages two days before the exam; and to wear light clothing without metal parts and have the bladder voided during the scan.

The determination of appendicular skeletal muscle mass (ASMM), i.e., the sum of the lean muscle mass of 
the arms and legs in $\mathrm{kg}$, was performed. ASMM was assessed as total ASMM (kg), adjusted for squared height (appendicular skeletal muscle mass index [ASMM I]) and for BMI (ASMM/BMI) [2, 6].

Hand grip strength (HGS) was assessed to obtain an approximation of the total body muscle strength [35]. The maximum HGS was determined using a hydraulic hand dynamometer (JAMAR ${ }^{\circ}$, Hand Dynamometer, Sammons Preston, Inc., Bolingbrook, IL) based on three consecutive measurements with a one-minute interval with the dominant upper limb in the orthostatic position and extended from the body. The maximum HGS value alone and adjusted for BMI (HGS/BMI) were included as outcome variables since they are variables included in the evaluation of sarcopenia $[4,35]$.

The walking speed test was performed to evaluate the individuals' functionality [36]. The test was conducted in an unobstructed 6-m-long flat corridor with cones indicating the course start and end points. The course was performed three times at the usual walking speed, with an average interval of one minute between each evaluation. The time required to go through the course was recorded using a digital timer, and the mean value of the obtained measurements was used for the classification $[36,37]$.

\section{Anthropometry}

Body weight was measured in kilograms using a calibrated digital electronic scale (WELMY@) with a capacity of up to $200 \mathrm{~kg}$ and a precision of $100 \mathrm{~g}$. Stature was determined using a stadiometer to the nearest 0.1 $\mathrm{cm}$. BMI was calculated according to the method stated by the World Health Organization (WHO) [38].

\section{Lifestyle}

A trained member of the research team applied a standardized questionnaire to record lifestyle variables including smoking, binge drinking, and physical activity. Smoking status was divided into non-smoker, smoker, and former smoker. The consumption of alcoholic beverages was assessed using an adapted version of the questionnaire used in the study Gender, Alcohol and Culture: An International Study (GENACIS). The binge drinking variable was evaluated based on the consumption of five drinks or more in a single occasion during the last year [39].

Physical activity was evaluated using a triaxial accelerometer (ActiGraph, wGT3X, Pensacola, FL, USA). The accelerometer was used for $24 \mathrm{~h}$ a day during six consecutive days over the non-dominant wrist, even during showers and water-based activities, as the device was waterproof. The sampling frequency of the accelerometer was set at $30 \mathrm{~Hz}$, and the data collection interval was set at one min. Accelerometers were set up and downloaded using ActiLife 6 software and data were processed using the R-package, GGIR (http://cran.r-project.org). The outcome measures used in the present study were moderate-to-vigorous physical activity ( $>100$ milligravities) defined as estimated time spent $\geq 10 \mathrm{~min}$ per bout during a week [40, 41].

\section{Health conditions and metabolic tests}

For the assessment of health conditions, the patients were asked if a medical doctor had ever diagnosed them with a certain disease on a list of diseases of interest for this study, answering yes or no. The presence of the disease was confirmed by the evaluation of the patients' medication and metabolic tests, as well as blood pressure levels. The health conditions evaluated were diabetes mellitus, hypertension, hypothyroidism, hypercholesterolemia, and menopause.

The presence of diabetes mellitus was verified using the evaluation of the use of hypoglycemic agents and/or fasting blood glucose $\geq 126 \mathrm{mg} / \mathrm{dl}$ and glycosylated hemoglobin (HbA1C) $\geq 6.5 \%$ [42]. The assessment of hypertension occurred based on the mean of two measurements of the systolic (SBP) and diastolic blood pressure (DBP) levels. Patients with SBP $\geq 140 \mathrm{mmHg}$ and/or DBP $\geq 90 \mathrm{mmHg}$ or who were using antihypertensive medication were considered hypertensive.

Hypothyroidism was assessed using thyroxine-based drugs and/or serum thyroid stimulating hormone $(\mathrm{TSH})>4.12 \mu \mathrm{g} / \mathrm{l}$ and free tetraiodothyronine $(\mathrm{T} 4)<0.7$ $\mathrm{ng} / \mathrm{dl}[33,34]$. The presence of menopause was investigated based on prior medical diagnosis through the question "Has a physician ever said that you are in menopause?" or the use of hormone replacement therapy. Hypercholesterolemia was defined as low-density lipoprotein cholesterol (LDL-c) $\geq 160 \mathrm{mg} / \mathrm{dl}$ [43].

The metabolic variables analyzed were total cholesterol (TC), high density lipoprotein cholesterol (HDL-c), LDLc, triglycerides (TG), serum vitamin D, TSH, T4, fasting blood glucose, HbA1C, C-reactive protein (CRP), and parathyroid hormone $(\mathrm{PTH})$. All variables were evaluated according to standardized reference methods [42-46].

\section{Food consumption}

For the evaluation of food consumption, the average nutrient consumption obtained from three 24-h recalls (24HR) was used. The calculation of the average intake of the nutrients of interest was performed using AVANUTRI software. Adequate micronutrient intake was evaluated according to the Estimated Average Requirement (EAR) for adults: vitamin $C \geq 75 \mathrm{mg} /$ day, vitamin $\mathrm{D} \geq 10 \mu \mathrm{g} /$ day, and vitamin $\mathrm{E} \geq 12 \mathrm{mg} /$ day [47]. The adequacy of macronutrients was assessed according to the Dietary Reference Intake (DRI) recommended ranges: $10-35 \%$ of the total energy intake of proteins and 20 $35 \%$ of lipids [47]. 


\section{Ethical aspects}

The HC/UFG Ethics Committee approved the study (protocol 747,792). The larger study was registered at ClinicalTrials.gov (NCT02463435). All participants read and signed the consent inform agreement document to be included in this study.

\section{Statistical analysis}

All statistical analysis was performed using Stata/SE 12.0. The outcomes of this study were the following sarcopenia-related variables: ASMMI $\left(\mathrm{kg} / \mathrm{m}^{2}\right)$, ASMM/ BMI, total ASMM (kg), HGS, and walking speed. All of them were analyzed as continuous variables. We considered the following explanatory variables: age, lifestyle, health conditions, food consumption, and metabolic parameters. The normality of continuous variables was evaluated using the Kolmogorov-Smirnov test. The descriptive analysis was expressed by mean and standard deviation (SD).

All variables with $p<0.20$ in the simple linear regression (SLR) were included in the multivariate linear regression model (MLR). In the MLR, variables were adjusted through elimination using the backward method. The level of statistical significance level was set at $p<0.05$.

\section{Results}

The study included 104 women with severe obesity (mean BMI, $43.85 \pm 4.53 \mathrm{~kg} / \mathrm{m}^{2}$ ); mean age, $40.23 \pm 8.49$ years, and average body fat percentage, $52.45 \pm 4.14 \%$. The mean and standard deviation of sarcopenia-related variables according to age is shown in Table 1.

The variables included in the MLR of the ASMMI outcome were smoking, menopause, and serum levels of TSH and T4. The variables included in the MLR of ASMM/BMI were age, diabetes, hypertension, menopause, and serum levels of HDL-c, T4 and HbA1C. Finally, the variables included in the MLR for the total ASMM were age, smoking, diabetes, menopause, and serum levels of T4 (Table 2).
The variables included in the MLR for the HGS outcome included age, excessive drinking, diabetes, hypercholesterolemia, menopause, vitamin $\mathrm{C}$ intake, and serum levels of HDL-c, LDL-c, and PTH. In the MLR for walking speed, the included variables comprise aerobic physical activity, diabetes, hypothyroidism, protein intake, and serum TSH and CRP. In the MLR for HGS/ BMI, the following variables were included: age, excessive drinking episodes, diabetes, hypertension, hypercholesterolemia, menopause, and serum levels of HDL-c, LDL-c, TG, HbA1C, and PTH (Table 3).

After MLR, ASMMI was negatively associated with serum levels of tetraiodothyronine (T4) and current smoker status. ASMM/BMI and total ASMM were negatively associated with serum T4 levels and the presence of diabetes $(p=0.006$ and $p=0.019)$. ASMM/BMI was also negatively associated with age (Table 4 ).

In the MLR model, HGS and HGS/BMI were negatively associated with age, the presence of hypercholesterolemia, and directly associated with serum LDL-c levels $(p=0.007)$. Walking speed was negatively associated with hypothyroidism $(p=0.042)$ and diabetes $(p=$ 0.005) (Table 5).

\section{Discussion}

To our knowledge, this is the first study to address the factors associated with different sarcopenia-related variables in adult women with severe obesity (class II/III). The assessment of factors associated with muscle mass, strength, and function contribute to the scientific knowledge in the area, mainly due to the wide variety of aspects that may be involved in the determination of the sarcopenia-related variables that were analyzed in the present study. In addition, it is a subject of great importance for women's health, since they are more affected than men by diseases related to obesity $[5,48]$.

Among the factors associated with low muscle mass, age, high T4 levels, smoking, and the presence of diabetes are noteworthy. Another relevant finding in our study was that HGS and HGS/BMI reduced with advancing age and the presence of hypercholesterolemia.

Table 1 Characterization of the evaluated sarcopenia-related variables according to age group

\begin{tabular}{|c|c|c|c|c|}
\hline & Total & $18-39$ years $N=49$ & $\geq 40$ years $N=55$ & \\
\hline Sarcopenia-related parameters & Mean \pm SD & Mean \pm SD & Mean \pm SD & $p^{*}$ \\
\hline ASMMI & $8.07 \pm 1.15$ & $7.98 \pm 1.04$ & $8.14 \pm 1.24$ & 0.473 \\
\hline ASMM/BMI & $0.47 \pm 0.09$ & $0.47 \pm 0.09$ & $0.45 \pm 0.08$ & 0.055 \\
\hline Total ASMM & $20.34 \pm 3.30$ & $20.78 \pm 3.42$ & $19.94 \pm 3.17$ & 0.201 \\
\hline HGS (Kgf) & $22.08 \pm 6.43$ & $23.02 \pm 6.48$ & $21.24 \pm 6.33$ & 0.159 \\
\hline HGS/BMI & $0.51 \pm 0.16$ & $0.54 \pm 0.16$ & $0.48 \pm 0.16$ & 0.083 \\
\hline Walking speed $(\mathrm{m} / \mathrm{s})$ & $1.02 \pm 0.18$ & $1.02 \pm 0.19$ & $1.01 \pm 0.17$ & 0.837 \\
\hline
\end{tabular}

Note. SD Standard Deviation, BMI Body Mass Index, ASMMI Appendicular Skeletal Muscle Mass Index, ASMM Total Appendicular Skeletal Muscle Mass, ASMM/BMI Total Appendicular Skeletal Muscle Mass/Body Mass Index, HGS Hand Grip Strength, HGS/BMI Hand Grip Strength/Body Mass Index, *Student's t-test 
Table 2 Simple linear regression of the explanatory variables according to different variables related to skeletal muscle mass

\begin{tabular}{|c|c|c|c|c|c|c|}
\hline & ASMMI & & ASMM/BN & & Total AS & \\
\hline & $\bar{B}$ & $p$ & $\bar{B}$ & $P$ & $\bar{B}$ & $p$ \\
\hline Age & -0.002 & 0.885 & -0.003 & 0.008 & -0.070 & 0.069 \\
\hline Smoking & -0.263 & 0.158 & -0.018 & 0.210 & -0.692 & 0.197 \\
\hline Binge drinking & -0.306 & 0.215 & -0.005 & 0.791 & -0.433 & 0.543 \\
\hline Physical activity & 0.003 & 0.249 & $<0.001$ & 0.682 & 0.006 & 0.458 \\
\hline Diabetes & -0.229 & 0.401 & -0.057 & 0.005 & -0.541 & 0.048 \\
\hline Hypertension & 0.116 & 0.608 & -0.026 & 0.137 & -0.079 & 0.903 \\
\hline Hypothyroidism & -0.188 & 0.466 & -0.009 & 0.645 & -0.408 & 0.583 \\
\hline Hypercholesterolemia & 0.117 & 0.741 & -0.002 & 0.929 & 0.130 & 0.899 \\
\hline Menopause & -0.475 & 0.111 & -0.041 & 0.068 & -0.974 & 0.020 \\
\hline Lipid intake & 0.007 & 0.703 & $<0.001$ & 0.831 & 0.362 & 0.467 \\
\hline Protein intake & -0.022 & 0.353 & $<-0.001$ & 0.763 & -0.044 & 0.515 \\
\hline Vitamin C intake & $<0.001$ & 0.654 & $<0.001$ & 0.590 & $<0.001$ & 0.621 \\
\hline Vitamin D intake & -0.006 & 0.257 & $<0.001$ & 0.927 & 0.018 & 0.218 \\
\hline Vitamin E intake & 0.007 & 0.632 & $<0.001$ & 0.955 & 0.032 & 0.440 \\
\hline Total cholesterol & -0.003 & 0.351 & $<-0.001$ & 0.640 & -0.004 & 0.669 \\
\hline HDL-C & -0.010 & 0.310 & -0.001 & 0.160 & -0.037 & 0.214 \\
\hline LDL-C & -0.002 & 0.531 & $<-0.001$ & 0.878 & -0.001 & 0.851 \\
\hline $\mathrm{TG}$ & $<0.001$ & 0.932 & 0.467 & 0.947 & 0.001 & 0.674 \\
\hline Serum vitamin $D$ & -0.002 & 0.852 & $<0.001$ & 0.976 & 0.002 & 0.947 \\
\hline TSH & 0.114 & 0.166 & $<-0.001$ & 0.878 & 0.213 & 0.368 \\
\hline $\mathrm{T} 4$ & -0.295 & 0.006 & -0.021 & 0.010 & -0.826 & 0.007 \\
\hline Fasting blood glucose & 0.002 & 0.521 & $<-0.001$ & 0.314 & $<0.001$ & 0.940 \\
\hline $\mathrm{HbA1C}$ & -0.043 & 0.596 & -0.010 & 0.111 & -0.270 & 0.253 \\
\hline CRP & 0.018 & 0.425 & 0.001 & 0.437 & 0.048 & 0.445 \\
\hline PTH & $<0.001$ & 0.962 & $<0.001$ & 0.418 & 0.013 & 0.307 \\
\hline
\end{tabular}

Note. BMI Body Mass Index, ASMMI Appendicular Skeletal Muscle Mass Index, ASMM Total Appendicular Skeletal Muscle Mass, ASMM/BMI Total Appendicular Skeletal Muscle Mass/Body Mass Index

Additionally, walking speed significantly reduced with the presence of diabetes and hypothyroidism.

The observed association between advancing age and decreased ASMM/BMI, HGS, and HGS/BMI is partly explained by the progressive reduction of anabolism and increased muscle catabolism associated with aging [49]. These events are accompanied by reduced muscle regeneration capacity, an imbalance in muscle protein turnover, and tissue remodeling [49]. The result of this process is the loss and atrophy of individual fibers as well as the loss of fast motor fibers (type II) and a size increase in the slow motor units (type I), with consequent development of muscle weakness and loss of fine movements. Aging-related decreased muscle mass is associated with quantitative and qualitative muscle loss, triggering functional imbalances marked by a decline in strength and functionality [50]. There are no previous studies in adults, obese or not obese, with which to compare the findings of this study. The results highlight the importance of the monitoring of lean mass in the adult population with obesity, since it is intrinsically related to possible disability and limitations.

The observed association between smoking and low ASMMI can be attributed to the influence of tobacco in promoting muscle catabolism [51]. Chronic exposure to cigarette smoke interferes with the signaling of skeletal muscle cells involved in protein homeostasis. These changes are influenced by the duration of exposure and may be reversible following smoking cessation [52]. The mechanisms involved in the low muscle mass of smokers include a reduction in the cross-sectional area of type I fibers, increased glycolytic enzymatic activity, and a decrease in the endothelial and neuronal activities of nitrite oxide synthetase when compared to those in non-smoking controls [53]. Smokers also present with higher levels of tumor necrosis factor alpha (TNF$\alpha)$, a potent inducer of skeletal muscle protein degradation [54]. 
Table 3 Simple linear regression of the explanatory variables according to different parameters of strength and walking speed

\begin{tabular}{|c|c|c|c|c|c|c|}
\hline & \multicolumn{2}{|l|}{ HGS } & \multicolumn{2}{|c|}{ HGS/BMI } & \multicolumn{2}{|c|}{ Walking speed } \\
\hline & $\bar{B}$ & $p$ & $\beta$ & $p$ & B & $p$ \\
\hline e & -0.171 & 0.021 & -0.005 & 0.006 & -0.002 & 0 \\
\hline imoking & 0.658 & 0.530 & 0.012 & 0.642 & -0.030 & 0.301 \\
\hline nge drinking & 0.150 & 0.147 & 0.051 & 0.142 & 0.037 & 0.340 \\
\hline Physical activity & -0.010 & 0.476 & -0.001 & 0.418 & 0.001 & 0.031 \\
\hline iabetes & -0.443 & 0.108 & -0.087 & 0.024 & -0.092 & 0.031 \\
\hline Hypertension & -0.381 & 0.277 & -0.058 & 0.069 & -0.038 & 0.283 \\
\hline ypothyroidism & -0.604 & 0.677 & -0.014 & 0.702 & -0.083 & 0.039 \\
\hline Hypercholesterolemia & -0.322 & 0.117 & -0.078 & 0.120 & 0.051 & 0.358 \\
\hline en & -0.177 & .025 & -0.084 & 0.046 & -0.041 & 0.386 \\
\hline pid intake & 0.035 & 0.721 & -0.001 & 0.935 & -0.001 & 0.977 \\
\hline rotein intake & 0.056 & 0.672 & 0.002 & 0.596 & 0.005 & 0.136 \\
\hline Jitamin C in & -0.003 & 198 & -0.001 & 0.225 & -0.001 & 0.828 \\
\hline /itamin D intake & -0.013 & 0.633 & 0.001 & 0.852 & -0.001 & 0.217 \\
\hline itamin E intake & 0.038 & 0.646 & 0.178 & 0.998 & -0.001 & 0.929 \\
\hline Total cholesterol & 0.017 & 0.340 & 0.001 & 0.376 & -0.001 & 0.810 \\
\hline$H D L-C$ & -0.093 & 0.107 & -0.002 & 0.111 & -0.001 & 0.829 \\
\hline LDL-C & 0.035 & 0.056 & 0.001 & 0.069 & 0.001 & 0.914 \\
\hline ГG & -0.011 & 0.212 & -0.001 & 0.179 & -0.001 & 0.245 \\
\hline Serum vitamin $D$ & -0.057 & 0.383 & -0.001 & 0.355 & -0.001 & 0.900 \\
\hline TSH & -0.134 & 0.772 & -0.008 & 0.482 & -0.033 & 0.008 \\
\hline 14 & -0.074 & 0.903 & -0.005 & 0.725 & 0.005 & 0.751 \\
\hline Fasting blood glucose & -0.011 & 0.494 & -0.001 & 0.201 & -0.001 & 0.654 \\
\hline $\mathrm{HbA1C}$ & -0.544 & 0.236 & -0.018 & 0.114 & 0.012 & 0.348 \\
\hline CRP & -0.033 & 0.784 & -0.001 & 0.963 & 0.010 & 0.009 \\
\hline TH & 0.059 & 0.015 & 0.001 & 0.036 & 0.001 & 0.202 \\
\hline
\end{tabular}

Note. BMI Body Mass Index, HGS Hand Grip Strength, HGS/BMI Hand Grip Strength/Body Mass Index
Histologically, sarcopenia is defined by muscle fiber atrophy, with high body fat responsible for fatty infiltration into the muscle tissue or lipid deposition within muscle fibers $[55,56]$. This occurs in some pathological conditions such as obesity, diabetes, and dyslipidemias [57]. The prevalence of sarcopenia is higher in patients with type 2 diabetes mellitus than in non-diabetic individuals [58]. In this study, diabetes was associated with a decrease in ASMM/BMI, ASMM, and slower walking speed. Such associations can be understood by the fact that skeletal muscle is the main tissue affected by disturbances in glucose metabolism, which, once reduced, triggers a functional decline. Metabolic signaling deficits in this tissue contribute to systemic insulin resistance directly affecting catabolic effects and glucose homeostasis, resulting in lower muscle mass $[59,60]$.

The association between elevated levels of $\mathrm{T} 4$ and reduced muscle mass (ASMMI, ASMM/BMI, and total ASMM) found in our study may be due to the action of thyroid hormones in the maintenance of the balance between anabolism and catabolism in cells and tissues, with the muscle tissue the preferred target for this process $[61,62]$. In the present study, an association between decreased functionality (walking speed) and the presence of hypothyroidism was identified. Both hypothyroidism and hyperthyroidism can lead to muscle mass loss and reduced functionality [63]. However, these relationships are not yet sufficiently clear. It is known that hormone treatment restores muscle mass and promotes an improvement in functionality. Thus, the diagnosis and early control of the disease becomes important $[64,65]$.

The excess of adipose tissue in obesity and presence of fat infiltration in muscle tissue may justify the association between the presence of hypercholesterolemia and the decrease in HGS and HGS/BMI. HGS reduction in sarcopenia is associated with increased serum levels of TC, TG, LDL-c, and decreased HDL-c [66, 67].

Table 4 Multiple linear regression adjusted by the explanatory variables for the different variables related to skeletal muscle mass

\begin{tabular}{|c|c|c|c|c|c|c|}
\hline & \multicolumn{2}{|l|}{ ASMMI } & \multicolumn{2}{|l|}{ ASMM/BMI } & \multicolumn{2}{|l|}{ Total ASMM } \\
\hline & $B(95 \% \mathrm{Cl})$ & $P$ & B $(95 \% \mathrm{Cl})$ & $p$ & $B(95 \% \mathrm{Cl})$ & $p$ \\
\hline Age & - & & $-0.002(-0.004--0.001)$ & 0.043 & - & \\
\hline \multicolumn{7}{|l|}{ Smoking* } \\
\hline Non-smokers & 1.00 & & - & & - & \\
\hline Former smokers & $-0.229(-0.807-0.349)$ & 0.433 & - & & - & \\
\hline Smokers & $-0.408(-0.804--0.012)$ & 0.044 & - & & - & \\
\hline \multicolumn{7}{|l|}{ Diabetes } \\
\hline No & - & & 1.00 & & 1.00 & \\
\hline Yes & - & & $-0.050(-0.92--0.008)$ & 0.019 & $-2.488(-4.230--0.746)$ & 0.006 \\
\hline $\mathrm{T} 4$ & $-0.243(-0.328--0.159)$ & $<0.001$ & $-0.019(-0.025--0.013)$ & $<0.001$ & $-0.674(-0.874--0.475)$ & $<0.001$ \\
\hline
\end{tabular}

Note. BMI Body Mass Index, ASMMI Appendicular Skeletal Muscle Mass Index, ASMM Total Appendicular Skeletal Muscle Mass, ASMM/BMI Total Appendicular Skeletal Muscle Mass/Body Mass Index, Cl Confidence Interval 
Table 5 Multiple linear regression adjusted by the explanatory variables for the variables used in the evaluation of gait force and walking speed. Goiânia, Goiás (Brazil), 2017 ( $n=104)$

\begin{tabular}{|c|c|c|c|c|c|c|}
\hline & \multicolumn{2}{|l|}{ HGS } & \multicolumn{2}{|l|}{ HGS/BMI } & \multicolumn{2}{|l|}{ Walking speed } \\
\hline & B $(95 \% \mathrm{Cl})$ & $p$ & B (95\% Cl) & $P$ & $B(95 \% \mathrm{Cl})$ & $p$ \\
\hline Age & $-0.182(-0.358--0.005)$ & 0.043 & $-0.005(-0.010--0.001)$ & 0.016 & - & \\
\hline \multicolumn{7}{|c|}{ Hypercholesterolemia } \\
\hline No & 1.00 & & 1.00 & & - & \\
\hline Yes & $-4.918(-8.725--1.112)$ & 0.012 & $-0.133(-0.238--0.029)$ & 0.012 & - & \\
\hline \multicolumn{7}{|c|}{ Hypothyroidism } \\
\hline No & - & & - & & 1.00 & \\
\hline Yes & - & & - & & $-0.119(-0.233--0.005)$ & 0.042 \\
\hline \multicolumn{7}{|c|}{ Diabetes } \\
\hline No & - & & - & & 1.00 & \\
\hline Yes & - & & - & & $-0.087(-0.148--0.026)$ & 0.005 \\
\hline LDL-C & $0.061(0.017-0.104)$ & 0.007 & $0.001(0.001-0.002)$ & 0.031 & - & \\
\hline
\end{tabular}

Note. BMI Body Mass Index, HGS Hand Grip Strength, HGS/BMI Hand Grip Strength/Body Mass Index, CI Confidence Interval

Furthermore, increased body adiposity contributes to the onset of different cardiometabolic diseases, such as type 2 diabetes and dyslipidemia. A vicious cycle of muscle loss and ectopic fat accumulation may be associated with the presence of these diseases, through a complex interaction of factors including proinflammatory cytokines, oxidative stress, mitochondrial dysfunction, insulin resistance, among other factors that may be involved in this process. However, without previous studies, it is difficult to draw some parallel [56].

Different clinical outcomes, such as increased risk of developing metabolic syndrome, difficulties in performing daily living activities of and mortality are related to muscle mass and low quality of muscle functions [35, $68,69]$. Recent evidence shows that low quality muscle mass is associated with the development of frailty in obese individuals [70]. The negative effects reported by different studies and our findings, such as a reduction in HGS in the presence of hypercholesterolemia, a decrease in walking speed with hypothyroidism and diabetes occurrence, and a reduction in muscle mass with T4 and diabetes, corroborate the simultaneous occurrence of the loss of muscle quality and negative metabolic outcomes and comorbidities in severely obese adults. Higher fat mass and substantial impairment of muscle mass and quality have interrelated and complex mechanisms with metabolic abnormalities [70]. This issue is relevant in the early diagnosis of and for clinical intervention in sarcopenic obese individuals.

The present study presents a significant contribution to the knowledge of the factors associated with the evaluation of sarcopenia in severely obese individuals, identifying variables with negatively related to muscle mass, strength, and function. There is still no consensus for an adequate evaluation and diagnosis of sarcopenia in adults with severe obesity $[6,14]$. Existing cutoff points for the diagnosis of sarcopenia are well defined for the elderly population and may constitute a possible limitation of the present study. However, in our analyses, we did not use cutoff points for the elderly, but average differences from the study population itself to minimize this issue. We emphasize that studies aimed to define cutoffs for adults are vital as sarcopenia has been reported in younger adults. Another possible limitation of our study is the size of the sample analyzed. However, considering the prevalence of severe obesity in the world population, the number of individuals recruited is considerable, given that other previous studies on this subject have a similar sample size to that of our study $[14,18]$.

\section{Conclusion}

We identified relevant and new risk factors to sarcopeniarelated variables in severely obese woman including age, smoking status, endocrine parameters (T4), hypercholesterolemia, and comorbidities such as diabetes and hypothyroidism. All these factors are negatively related to muscle mass, strength, and function. Thus, the results of this investigation are relevant in supporting the development of clinical interventions to aid in the prevention of sarcopenia in adults with severe obesity. Our findings are a relevant contribution to the elaboration of clinical intervention policies aimed at preventing loss of muscle mass and functional impairment, physical disability, decreased strength, and muscular endurance in severely obese women. Additional studies with a longitudinal design are necessary to confirm the results found here.

Abbreviations

24HR: 24-h recall; ASMM: Appendicular skeletal muscle mass; ASMM/ BMl: Appendicular skeletal muscle mass adjusted by BMl;

ASMMI: Appendicular skeletal muscle mass index; TC: Cholesterol; CRP: C- 
reactive protein; DRI: Dietary Reference Intake; EAR: Estimated Average Requirement; DXA: Evaluated by dual energy X-ray absorptiometry; HGS: Hand grip strength; HDL-c: High density lipoprotein cholesterol; PTH: Parathyroid hormone; T4: Tetraiodothyronine; TG: Triglycerides; WS: Walking speed; WHO: World Health Organization

\section{Acknowledgments}

The authors would like to thank the National Council for Scientific and Technological Development of Brazil (CNPq), the Study Group on Severe Obesity (GEOG) and the Instituto Federal Goiano for funding this study.

\section{Authors' contributions}

The authors' contributions are as follows: EAS conceptual idea; EAS and JDS designed and conducted the research; EAS, JDS, ASACS, ABSC, MN, and VP analyzed the data, interpreted the results, and wrote the paper. All authors read and approved the final paper. EAS is the principal investigator of this research project (DieTBra Trial) and received a grant from FAPEG.

\section{Funding}

This study was supported by FAPEG Foundation (grant number 201310267000003)

\section{Availability of data and materials}

The datasets used and/or analyzed during the current study are available from the corresponding author on request.

\section{Ethics approval and consent to participate}

The HC/UFG Ethics Committee approved the study (protocol 747,792). The larger study was registered at the ClinicalTrials.gov (NCT02463435).

\section{Consent for publication}

Not applicable.

\section{Competing interests}

The authors declare no conflict of interest.

\section{Author details}

'Health Science Post-Graduation Program, Faculty of Medicine, Universidade Federal de Goiás, 1a. s/n - Setor Leste Universitário, Goiânia, Goiás CEP 74605-020, Brazil. ${ }^{2}$ University North of Paraná, Londrina, Brazil. ${ }^{3}$ Faculty of Nursing, Universidade Federal de Goiás, Goiânia, Brazil. ${ }^{4}$ Instituto Federal Goiano, Goiânia, Brazil.

\section{Received: 6 April 2020 Accepted: 28 July 2020}

\section{Published online: 03 August 2020}

\section{References}

1. Epidemiologic and methodologic problems in determining nutritional status of older persons. Proceedings of a conference. Albuquerque, New Mexico, October 19-21, 1988. Am J Clin Nutr. 1989;50: 1121-235. Available: http://www.ncbi.nlm.nih.gov/pubmed/2816807.

2. Cherin P, Voronska E, Fraoucene N, de Jaeger C. Prevalence of sarcopenia among healthy ambulatory subjects: the sarcopenia begins from 45 years. Aging Clin Exp Res. 2014;26:137-46. https://doi.org/10.1007/s40520-0130132-8.

3. Pagotto V, Silveira EA. Methods, diagnostic criteria, cutoff points, and prevalence of sarcopenia among older people. Sci World J. 2014:2014:1-11. https://doi.org/10.1155/2014/231312.

4. Studenski SA, Peters KW, Alley DE, Cawthon PM, McLean RR, Harris TB, et al. The FNIH sarcopenia project: rationale, study description, conference recommendations, and final estimates. J Gerontol Ser A. 2014;69:547-58. https://doi.org/10.1093/gerona/glu010.

5. Bosy-Westphal A, Müller MJ. Identification of skeletal muscle mass depletion across age and BMl groups in health and disease - there is need for a unified definition. Int J Obes. 2015;39:379-86. https://doi.org/10.1038/ijo. 2014.161.

6. Cruz-Jentoft AJ, Bahat G, Bauer J, Boirie $Y$, Bruyère $O$, Cederholm T, et al. Sarcopenia: revised European consensus on definition and diagnosis. Age Ageing. 2019;48:16-31. https://doi.org/10.1093/ageing/afy169.
7. Roubenoff R. Sarcopenic obesity: does muscle loss cause fat gain?: lessons from rheumatoid arthritis and Osteoarthritisa. Ann N Y Acad Sci. 2006;904: 553-7. https://doi.org/10.1111/j.1749-6632.2000.tb06515.x.

8. Roubenoff R. Sarcopenic obesity: the confluence of two epidemics. Obes Res. 2004;12:887-8. https://doi.org/10.1038/oby.2004.107.

9. Silveira EA, Ferreira CCDC, Pagotto V, Santos ASEADC, Velasquez-Melendez G. Total and central obesity in elderly associated with a marker of undernutrition in early life - sitting height-to-stature ratio: A nutritional paradox. Am J Hum Biol. 2017;29:e22977. https://doi.org/10.1002/ajhb.22977.

10. Cauley JA. An overview of Sarcopenic obesity. J Clin Densitom. 2015;18:499505. https://doi.org/10.1016/j.jocd.2015.04.013.

11. Batsis JA, Mackenzie TA, Barre LK, Lopez-Jimenez F, Bartels SJ. Sarcopenia, sarcopenic obesity and mortality in older adults: results from the National Health and nutrition examination survey III. Eur J Clin Nutr. 2014;68:1001-7. https://doi.org/10.1038/ejcn.2014.117.

12. Abarca-Gómez L, Abdeen ZA, Hamid ZA, Abu-Rmeileh NM, Acosta-Cazares B, Acuin C, et al. Worldwide trends in body-mass index, underweight, overweight, and obesity from 1975 to 2016: a pooled analysis of 2416 population-based measurement studies in 128.9 million children, adolescents, and adults. Lancet. 2017;390:2627-42. https://doi.org/10.1016/ S0140-6736(17)32129-3.

13. Kob R, Bollheimer LC, Bertsch T, Fellner C, Djukic M, Sieber CC, et al. Sarcopenic obesity: molecular clues to a better understanding of its pathogenesis? Biogerontology. 2015;16:15-29. https://doi.org/10.1007/ s10522-014-9539-7.

14. Johnson Stoklossa CA, Sharma AM, Forhan M, Siervo M, Padwal RS, Prado CM. Prevalence of Sarcopenic obesity in adults with class II/III obesity using different diagnostic criteria. J Nutr Metab. 2017;2017:1-11. https://doi.org/10. 1155/2017/7307618

15. Fukuda T, Bouchi R, Takeuchi T, Tsujimoto K, Minami I, Yoshimoto T, et al. Sarcopenic obesity assessed using dual energy $\mathrm{X}$-ray absorptiometry (DXA) can predict cardiovascular disease in patients with type 2 diabetes: a retrospective observational study. Cardiovasc Diabetol. 2018;17:55. https:// doi.org/10.1186/s12933-018-0700-5.

16. Schautz B, Later W, Heller M, Müller MJ, Bosy-Westphal A. Total and regional relationship between lean and fat mass with increasing adiposity_impact for the diagnosis of sarcopenic obesity. Eur J Clin Nutr. 2012;66:1356-61. https://doi.org/10.1038/ejcn.2012.138.

17. De Rosa E, Santarpia L, Marra M, Sammarco R, Amato V, Onufrio M, et al. Preliminary evaluation of the prevalence of sarcopenia in obese patients from southern Italy. Nutrition. 2015;31:79-83. https://doi.org/10.1016/j.nut. 2014.04.025.

18. Godziuk K, Prado CM, Woodhouse LJ, Forhan M. Prevalence of sarcopenic obesity in adults with end-stage knee osteoarthritis. Osteoarthr Cartil. 2019; 27:1735-45. https://doi.org/10.1016/j.joca.2019.05.026.

19. Zamboni M, Rubele S, Rossi AP. Sarcopenia and obesity. Curr Opin Clin Nutr Metab Care. 2018;1. https://doi.org/10.1097/MCO.0000000000000519.

20. Du Y, Oh C, No J. Associations between sarcopenia and metabolic risk factors: a systematic review and meta-analysis. J Obes Metab Syndr. 2018;27: 175-85. https://doi.org/10.7570/jomes.2018.27.3.175.

21. Jackson MJ. Strategies for reducing oxidative damage in ageing skeletal musclesł. Adv Drug Deliv Rev. 2009;61:1363-8. https://doi.org/10.1016/j. addr.2009.07.018.

22. Liochev SI. Reactive oxygen species and the free radical theory of aging. Free Radic Biol Med. 2013;60:1-4. https://doi.org/10.1016/j.freeradbiomed. 2013.02.011.

23. Petermann-Rocha F, Chen M, Gray SR, Ho FK, Pell JP, Celis-Morales C. Factors associated with sarcopenia: a cross-sectional analysis using UK biobank. Maturitas. 2020;133:60-7. https://doi.org/10.1016/j.maturitas.2020.01.004.

24. Yoo S, Kim D-Y, Lim H. Sarcopenia in relation to nutrition and lifestyle factors among middle-aged and older Korean adults with obesity. Eur J Nutr. 2020. https://doi.org/10.1007/s00394-020-02179-3.

25. Maltais ML, Desroches J, Dionne IJ. Changes in muscle mass and strength after menopause. J Musculoskelet Neuronal Interact. 2009:9:186-97. https:// europepmc.org/article/med/19949277.

26. Vilaça KHC, Carneiro JAO, Ferriolli E, da Costa Lima NK, de Paula FJA, Moriguti JC. Body composition, physical performance and muscle quality of active elderly women. Arch Gerontol Geriatr. 2014;59:44-8. https://doi.org/ 10.1016/j.archger.2014.02.004..

27. Nezameddin R, Itani L, Kreidieh D, El Masri D, Tannir H, El Ghoch M. Understanding sarcopenic obesity in terms of definition and health 
consequences: a clinical review. Curr Diabetes Rev. 2020;16. https://doi.org/ 10.2174/1573399816666200109091449.

28. Santos ASAC, Rodrigues APS, Rosa LPS, Sarrafzadegan N, Silveira EA. Cardiometabolic risk factors and Framingham risk score in severely obese patients: baseline data from DieTBra trial. Nutr Metab Cardiovasc Dis. 2020 30:474-82. https://doi.org/10.1016/j.numecd.2019.10.010.

29. Rodrigues APS, Rosa LPS, Silveira EA. PPARG2 Pro12Ala polymorphism influences body composition changes in severely obese patients consuming extra virgin olive oil: a randomized clinical trial. Nutr Metab (Lond). 2018;15:52. https://doi.org/10.1186/s12986-018-0289-4.

30. Rodrigues APDS, Rosa LPS, Silva HDD, Silveira-Lacerda EDP, Silveira EA. The single nucleotide polymorphism PPARG2 Pro12Ala affects body mass index, fat mass, and blood pressure in severely obese patients. J Obes. 2018;2018: 1-9. https://doi.org/10.1155/2018/2743081.

31. Batista de Sousa Canheta A, de Carvalho Santos AS e A, Danésio de Souza J, Silveira EA. Traditional Brazilian diet and extra virgin olive oil reduce symptoms of anxiety and depression in individuals with severe obesity: randomized clinical trial. Clin Nutr. 2020. https://doi.org/10.1016/j.clnu.2020. 05.046.

32. Cardoso CKDS, Santos AS e A de C, Rosa LPDS, Mendonça CR, Vitorino PVDO, Peixoto MDRG, et al. Effect of Extra Virgin Olive Oil and Traditional Brazilian Diet on the Bone Health Parameters of Severely Obese Adults: A Randomized Controlled Trial. Nutrients. 2020;12:403. https://doi.org/10.3390/ nu12020403.

33. Aparecida Silveira E, Danésio de Souza J, dos Santos Rodrigues AP, Lima RM, de Souza Cardoso CK, de Oliveira C. Effects of Extra Virgin Olive Oil (EVOO) and the Traditional Brazilian Diet on Sarcopenia in Severe Obesity: A Randomized Clinical Trial. Nutrients. 2020;12:1498. https:/doi.org/10.3390/ nu12051498.

34. Santos ASEADC, Rodrigues APDS, Rosa LPDS, Noll M, Silveira EA. Traditional Brazilian Diet and Olive Oil Reduce Cardiometabolic Risk Factors in Severely Obese Individuals: A Randomized Trial. Nutrients. 2020;12:1413. https://doi. org/10.3390/nu12051413.

35. Lauretani F, Russo CR, Bandinelli S, Bartali B, Cavazzini C, Di lorio A, et al. Age-associated changes in skeletal muscles and their effect on mobility: an operational diagnosis of sarcopenia. J Appl Physiol. 2003;95:1851-60. https:// doi.org/10.1152/japplphysiol.00246.2003.

36. Kollen B, Kwakkel G, Lindeman E. Hemiplegic gait after stroke: is measurement of maximum speed required? Arch Phys Med Rehabil. 2006; 87:358-63. https://doi.org/10.1016/j.apmr.2005.11.007.

37. Cesari M, Kritchevsky SB, Newman AB, Simonsick EM, Harris TB, Penninx BW, et al. Added value of physical performance measures in predicting adverse health-related events: results from the health, aging and body composition study. J Am Geriatr Soc. 2009;57:251-9. https://doi.org/10.1111/j.1532-5415. 2008.02126.x.

38. World Health Organization (WHO). Obesity and overweight. World Health Organization; 2015.

39. World Health Organization (WHO). Alcohol, gender and drinking problems: perspectives from low and middle income countries. 2005.

40. Dillon CB, Fitzgerald AP, Kearney PM, Perry IJ, Rennie KL, Kozarski R, et al. Number of Days Required to Estimate Habitual Activity Using Wrist-Worn GENEActiv Accelerometer: A Cross-Sectional Study. Buchowski M, editor. PLoS One. 2016;11: e0109913. doi:https:/doi.org/10.1371/journal.pone.0109913.

41. World Health Organization (WHO). Global recommendations on physical activity for health. Switzerland; 2010.

42. 2 Classification and Diagnosis of Diabetes. Standards of Medical Care in Diabetes-2018. Diab Care. 2018;41:S13-27. https://doi.org/10.2337/dc18S002.

43. Xavier HT, Izar MC, Faria Neto JR, Assad MH, Rocha VZ, Sposito AC, et al. V Diretriz Brasileira de Dislipidemias e Prevenção da Aterosclerose. Arq Bras Cardiol. 2013;101:01-22. https://doi.org/10.5935/abc.20135010.

44. Garber JR, Cobin RH, Gharib H, Hennessey JV, Klein I, Mechanick Jl, et al. Clinical practice guidelines for hypothyroidism in adults: cosponsored by the American Association of Clinical Endocrinologists and the American Thyroid Association. Endocr Pract. 2012;18:988-1028. https://doi.org/10.415 8/EP12280.GL.

45. Maeda SS, Borba VZC, Camargo MBR, Silva DMW, Borges JLC, Bandeira F, et al. Recomendações da Sociedade Brasileira de Endocrinologia e Metabologia (SBEM) para o diagnóstico e tratamento da hipovitaminose D. Arq Bras Endocrinol Metabol. 2014;58:411-33. https://doi.org/10.1590/00042730000003388
46. Marcocci C, Cetani F. Primary hyperparathyroidism. N Engl J Med. 2011;365: 2389-97. https://doi.org/10.1056/NEJMcp1106636.

47. Dietary Reference Intakes for Energy, Carbohydrate, Fiber, Fat, Fatty Acids, Cholesterol, Protein, and Amino Acids. Washington, D.C.: National Academies Press; 2005. doi:https://doi.org/10.17226/10490.

48. Delmonico MJ, Harris TB, Lee J-S, Visser M, Nevitt M, Kritchevsky SB, et al. Alternative definitions of sarcopenia, lower extremity performance, and functional impairment with aging in older men and women. J Am Geriatr Soc. 2007;55:769-74. https://doi.org/10.1111/j.1532-5415.2007.01140.x.

49. Tudoraşcu I, Sfredel V, Riza AL, Dănciulescu Miulescu R, lanoşi SL, Dănoiu S. Motor unit changes in normal aging: a brief review. Rom J Morphol Embryol. 2014;55:1295-301 Available: http://www.ncbi.nlm.nih.gov/ pubmed/25611259.

50. Fragala MS, Kenny AM, Kuchel GA. Muscle quality in aging: a multidimensional approach to muscle functioning with applications for treatment. Sport Med. 2015;45:641-58. https://doi.org/10.1007/s40279-0150305-z.

51. Rom O, Kaisari S, Aizenbud D, Reznick AZ. Sarcopenia and smoking: a possible cellular model of cigarette smoke effects on muscle protein breakdown. Ann N Y Acad Sci. 2012;1259:47-53. https://doi.org/10.1111/j. 1749-6632.2012.06532.x.

52. Caron M-A, Morissette MC, Thériault M-E, Nikota JK, Stämpfli MR, Debigaré R. Alterations in Skeletal Muscle Cell Homeostasis in a Mouse Model of Cigarette Smoke Exposure. Thatcher TH, editor. PLoS One. 2013;8: e66433. doi:https://doi.org/10.1371/journal.pone.0066433.

53. Rom O, Kaisari S, Aizenbud D, Reznick AZ. Identification of possible cigarette smoke constituents responsible for muscle catabolism. J Muscle Res Cell Motil. 2012;33:199-208. https://doi.org/10.1007/s10974-012-9299-4.

54. Tanni SE, Pelegrino NR, Angeleli AY, Correa C, Godoy I. Smoking status and tumor necrosis factor-alpha mediated systemic inflammation in COPD patients. J Inflamm. 2010;7:29. https://doi.org/10.1186/1476-9255-7-29.

55. Sakuma K, Yamaguchi A. Sarcopenic obesity and endocrinal adaptation with age. Int J Endocrinol. 2013;2013:1-12. https://doi.org/10.1155/2013/204164.

56. Kim TN, Choi KM. The implications of sarcopenia and Sarcopenic obesity on Cardiometabolic disease. J Cell Biochem. 2015;116:1171-8. https://doi.org/ 10.1002/jcb.25077.

57. Vettor R, Milan G, Franzin C, Sanna M, De Coppi P, Rizzuto R, et al. The origin of intermuscular adipose tissue and its pathophysiological implications. Am J Physiol Metab. 2009;297:E987-98. https://doi.org/10.1152/ ajpendo.00229.2009.

58. Kim TN, Park MS, Yang SJ, Yoo HJ, Kang HJ, Song W, et al. Prevalence and determinant factors of sarcopenia in patients with type 2 diabetes: the Korean Sarcopenic obesity study (KSOS). Diabetes Care. 2010;33:1497-9. https://doi.org/10.2337/dc09-2310.

59. Azuma K, Heilbronn LK, Albu JB, Smith SR, Ravussin E, Kelley DE, et al. Adipose tissue distribution in relation to insulin resistance in type 2 diabetes mellitus. Am J Physiol Endocrinol Metab. 2007;293:E435-42. https://doi.org/10.1152/ajpendo.00394.2006.

60. Mogi M, Kohara K, Nakaoka H, Kan-No H, Tsukuda K, Wang X-L, et al. Diabetic mice exhibited a peculiar alteration in body composition with exaggerated ectopic fat deposition after muscle injury due to anomalous cell differentiation. J Cachexia Sarcopenia Muscle. 2016;7:213-24. https://doi. org/10.1002/jcsm.12044.

61. Moon MK, Lee YJ, Choi SH, Lim S, Yang EJ, Lim J-Y, et al. Subclinical hypothyroidism has little influences on muscle mass or strength in elderly people. J Korean Med Sci. 2010;25:1176. https://doi.org/10.3346/jkms.2010. 25.8.1176.

62. Bjergved L, Jørgensen T, Perrild H, Laurberg P, Krejbjerg A, Ovesen L, et al. Thyroid Function and Body Weight: A Community-Based Longitudinal Study. Timpson NJ, editor. PLoS One. 2014;9: e93515. doi:https://doi.org/10. 1371/journal.pone.0093515.

63. Brennan MD, Powell C, Kaufman KR, Sun PC, Bahn RS, Nair KS. The impact of overt and subclinical hyperthyroidism on skeletal muscle. Thyroid. 2006;16: 375-80. https://doi.org/10.1089/thy.2006.16.375.

64. O'Leary PC, Feddema PH, Michelangeli VP, Leedman PJ, Chew GT, Knuiman $\mathrm{M}$, et al. Investigations of thyroid hormones and antibodies based on a community health survey: the Busselton thyroid study. Clin Endocrinol (Oxf). 2006:64:97-104. https://doi.org/10.1111/j.1365-2265.2005.02424.x.

65. Ruchała M, Stangierski A, Krauze T, Moczko J, Guzik P. Zmiany w składzie tkankowym obserwowane w trakcie terapii ciężkich zaburzeń funkcji tarczycy. Endokrynol Pol. 2015. https://doi.org/10.5603/EP.a2016.0025. 
66. Baek SJ, Nam GE, Han KD, Choi SW, Jung SW, Bok AR, et al. Sarcopenia and sarcopenic obesity and their association with dyslipidemia in Korean elderly men: the 2008-2010 Korea National Health and nutrition examination survey. J Endocrinol Investig. 2014;37:247-60. https://doi.org/10.1007/ s40618-013-0011-3.

67. Kim TN, Park MS, IL LK, Yang SJ, Yoo HJ, Kang HJ, et al. Skeletal muscle mass to visceral fat area ratio is associated with metabolic syndrome and arterial stiffness: The Korean Sarcopenic Obesity Study (KSOS). Diab Res Clin Pract. 2011;93:285-91. https://doi.org/10.1016/j.diabres.2011.06.013.

68. Crispim Carvalho NN, Baccin Martins VJ, Modesto-Filho J, Bandeira F, Fernandes Pimenta FC, de Brito Alves JL. Relationship between skeletal muscle mass indexes and muscular function, metabolic profile and bone mineral density in women with recommendation for bariatric surgery. Diab Metab Syndr Obes Targets Ther. 2019;12:2645-54. https://doi.org/10.2147/ DMSO.S213643.

69. de Oliveira Máximo R, JLF S, Perracini MR, de Oliveira Duarte YA, da Silva Alexandre T, et al. Brazilian J Phys Ther. 2019;23:497-505. https://doi.org/10. 1016/j.bjpt.2018.10.009.

70. Barazzoni R, Bischoff S, Boirie Y, Busetto L, Cederholm T, Dicker D, et al. Sarcopenic obesity: time to meet the challenge. Obes Facts. 2018;11:294305. https://doi.org/10.1159/000490361.

\section{Publisher's Note}

Springer Nature remains neutral with regard to jurisdictional claims in published maps and institutional affiliations.

Ready to submit your research? Choose BMC and benefit from:

- fast, convenient online submission

- thorough peer review by experienced researchers in your field

- rapid publication on acceptance

- support for research data, including large and complex data types

- gold Open Access which fosters wider collaboration and increased citations

- maximum visibility for your research: over $100 \mathrm{M}$ website views per year

At BMC, research is always in progress.

Learn more biomedcentral.com/submissions 